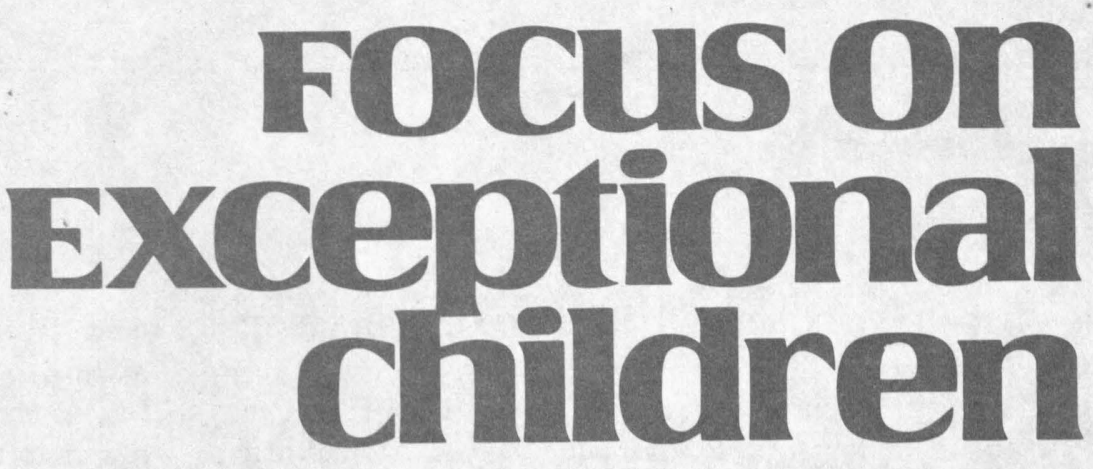

\title{
Classroom Management: Teacher-Child-Peer Relationships
}

James M. Kauffman, Patricia L. Pullen, and Eileen Akers

Most teachers spend little or none of their teaching time in concentrating solely on an individual student, whether for academic instruction or behavior management. The reality of the classroom demands that teachers instruct and manage students in groups. Moreover, research indicates that the most effective instruction typically occurs in small groups, with the teacher requiring both group and individual responses (Stevens \& Rosenshine, 1981; Wallace \& Kauffman, 1986). Although special education is concerned with individuals, the notion of individualization often has been misunderstood and misapplied to special education (Lloyd, 1984; Strain, Odom, \& McConnell, 1984). In short, both instruction and behavior management in the classroom almost always involve a teacher, an exceptional child, and the child's peers. When a classroom management problem arises, all three-teacher, child, and peers-are very much in it together.

The "togetherness" involved in problem behavior was first emphasized by special educators who described classrooms as microcommunities or social ecologies (e.g., Graubard, Rosenberg, \& Miller, 1971; Hobbs, 1966; Rhodes, 1967, 1970). Research based on the ecological principles of mutual influence and interdependency has clearly established the fact that every person in the classroom-adult or child-influences the behavior of every other individual in that environment (Kauffman, 1985). Thus, classroom management strategies must take into account not only the teacher's influence on children but children's influence on the teacher and on each other as well.

Relationships among teachers, children, and peers suggest looking for mutual influences in the causes of misbehavior; they suggest also an array of strategies, including direct management by the teacher, self-control techniques, and peer-directed interventions. We will briefly examine potential contributions to misbehavior on the part of teachers and children; then we will describe possible interventions.

James Kauffman is Professor of Education, Department of Curriculum, Instruction, and Special Education, Curry School of Education, University of Virginia, Charlottesville. Patricia Pullen is a clinical instructor in the Curry School and a special education teacher at Jackson Via Elementary School, Charlottesville. Eileen Akers is a clinical instructor in the Curry School, president of the Charlottesville Education Association, and a first grade teacher at Jackson Via Elementary School.

CLove Publishing Company 1986. 


\section{POTENTIAL CONTRIBUTIONS TO MISBEHAVIOR}

When children misbehave, adults may be a part of the problem. Through their expectations, demands, and reactions to children's behavior, adults influence the course of interactions for better or for worse. Adults thus bear much responsibility for how children behave. Teachers, as are parents, are called upon to shape children's behavior through their conscious manipulation of the child's physical and social environment. Teachers' tasks include selecting curriculum, giving directions, setting expectations, controlling consequences, and otherwise structuring the environment to obtain and support desirable conduct.

Nevertheless, children share responsibility for their misbehavior. They are not merely passive recipients of adults' manipulations. Children are active partners in determining how they are treated by their parents, teachers, and peers. Their physical, cognitive, and behavioral characteristics play a significant role in determining how others will approach

\section{FOCus on Exceptional children}

FOCUS ON EXCEPTIONAL CHILDREN (ISSN0015-51IX) (USPS 203-360) is published monthly except June, July, and August as a service to teachers, special educators, curriculum specialists, administrators, and those concerned with the special education of exceptional children. This journal is abstracted and indexed in Exceptional Child Education Resources, and is also available in microform from Xerox University Microfilm. Ann Arbor, Michigan. Subscription rates, $\$ 24.00$ per year. Copyright $\odot 1986$, Love Publishing Company. All rights reserved. Reproduction in whole or part without written permission is prohibited. Printed in the United States of America. Second class postage is paid at Denver, Colorado.

POSTMASTER: Send address changes to:

Love Publishing Company

Executive and Editorial Office

1777 South Bellaire Street

Denver, Colorado 80222

Telephone (303) 757-2579

EDITORIAL BOARD
Edward L. Meyen

University of Kansas

Richard J. Whelan

Glenn A. Vergason

Georgia State University

University of Kansas Medical Center
Carolyn Acheson Senior Editor them, what others will expect of them, and how others will respond to them. Their developmental tasks include learning how to encourage others to approach them and how to be rewarding to others-in short, how to join appropriate "communities of reinforcement," how to become enmeshed in mutually gratifying and appropriate social exchanges (Strain, Odom, \& McConnell, 1984).

When misbehavior occurs, teachers too often assign an unrealistic burden of responsibility to themselves or to children. Teachers must, certainly, assume primary responsibility for analysis of and intervention in troublesome behavior. To blame the child, to see the problem as hopeless or the child as simply unmanageable, is all too easy. In this era of emphasis on the accountability of teachers, however, the following should be remembered: Inadequate teaching is not the only possible cause of a child's academic or social problems. We should examine, therefore, the major contributions that both teachers and children can make to problems of classroom management.

\section{Teachers' Contributions}

The child development literature and research in classrooms indicate, as Kauffman (1985) has noted, a variety of ways in which teachers may contribute to children's misbehavior. Both the research literature and our classroom experience suggest that the following teacher characteristics will negatively influence classroom discipline and learning:

- inconsistency in management techniques

- reinforcement of the wrong behavior

- formation of inappropriate expectations for children

- nonfunctional or irrelevant instruction

- insensitivity to children's legitimate individuality

- demonstration or encouragement of undesirable models

- irritability and overreliance on punishment

- unwillingness to try new strategies or to seek suggestions from other professionals.

Teachers certainly do not purposely encourage children to misbehave, but they sometimes have blind spots in their classrom management practices that set the stage for behavior problems. Figure 1 is a checklist for teachers; it is intended to encourage introspection and self-monitoring that may indicate how the classroom environment might be altered to reduce the probability that problems will arise or continue. 
FIGURE 1

Possible Contributions to Misbehavior: A Checklist of Teacher Behavior

Am I consistent in responding to children's behavior? If your response to children's conduct-good or bad-is unpredictable, children will have difficulty learning how they are to behave. Your students should know what the consequences of appropriate behavior and misbehavior will be. Give clear directions; hold firm to your expectations; and be consistent in following through with rewards and punishment.

Am I rewarding the right behavior? Children who present difficult management problems often are ingnored when they are behaving appropriately. Often, about the only time they receive attention is when they are criticized or reprimanded for misbehavior. Sometimes teachers make the mistake of praising them (for something else) or making physical contact with them (in attempts to offer loving correction) when they misbehave. Make sure that children are receiving your attention primarily when they are behaving appropriately. You must make certain that desirable conduct receives a hefty amount of recognition and that misbehavior does not.

Are my expectations and demands appropriate for children's abilities? When expectations are too high, children feel too much pressure and experience too much failure. When expectations are too low, children become bored and may feel resentful. Make certain that your expectations fit each child's ability level so that the child is challenged while his or her progress is obvious.

Am I tolerant enough of children's individuality? Children have as much right as adults to express their individuality. Many children rebel against teachers who demand strict uniformity and regimentation or are unwilling to encourage appropriate individuality. Make certain that your rules and expectations allow sufficient room for harmless preferences and idiosyncracies.
Am I providing instruction that is useful to children? People do not learn quickly or happily when they see no point in what they are doing. First, you must make sure that you have chosen the most important things to teach. When children do not see the importance of what you are teaching, you must point out to them the value of what they are learning. If they still do not understand, you must find a way to make the material interesting or worth their while-perhaps by offering meaningful rewards of privileges for learning.

Are children seeing desirable models? Children are great imitators of their teachers and their high-status peers. Make certain that if chidren are imitating you, they are behaving appropriately. Monitor your own behavior, and change it if necessary. Call attention to the desirable conduct of children's peers. Point out the kind of behavior you want to see.

Am I generally irritable and overreliant on punishment as a control technique? Teachers set a tone in their classrooms by thier general attitudes toward persons and events. A teacher who is easily upset, frequently short-tempered, quick to punish minor misbehavior, and hesitant in expressing approval is virtually certain to foster irritability and defiance in students. General irritability and a focus on punishment suggest depression; and a teacher's depression may contribute to children's depressive behavior.

Am I willing to try a different tack on the problem or to seek the help of colleagues or consultants? A teacher who resists the suggestions of others, who insists on "going it alone," or who discards any different approach as useless or doomed to failure is not likely to be successful for long. Teaching today presents complex behavior management problems for which even the most competent teacher needs consultation. An attitude of openness and a willingness to look outside oneself are essential to success. 


\section{Children's Contributions}

The work of Swift and Spivack $(1969,1973)$ and others has indicated differences between the behavior of poor achievers and the behavior of high achievers in elementary and secondary schools. The behavioral characteristics of low achievers not only inhibit or preclude academic success, but they produce stress in the teacher and peers as well. Following are some of the most common characteristics known to contribute to academic and behavior management problems:

- overdependency on the teacher

- difficulty concentrating and paying attention

- becoming upset under pressure to achieve

- sloppiness and impulsivity in responding

- teasing, annoying, or interfering with other children

- negativism about work, self, teacher, or peers

- poor personal hygiene

- extreme social withdrawal or refusal to respond

- self-stimulation or self-injury

- physical or verbal aggression toward teacher or peers.

Teachers should not be suprised that these characteristics call forth negative affect and behavior from a child's peers or from themselves. These and similar characteristics suggest targets for behavioral intervention. Figure 2 includes items that a teacher might use as a checklist in considering the selection of behaviors for intervention.

\section{INTERVENTIONS}

When behavior management problems arise in the classroom, one should consider first the possible contributions that the teacher, the child, and peers are making to the difficulty. Even if the teacher's self-assessment or the assessment of a colleague or consultant leads to the conclusion that the teacher's behavior is exemplary for highly competent professionals, intervention must begin with a change in teacher behavior. A different strategy must be tried. We offer several suggestions for the selection of interventions.

Perhaps the most useful suggestion we can make is that the simplest, most direct approaches to solving the problem should be tried first. If simple instructions, reminders, or models of appropriate behavior will suffice, more complicated interventions are a waste of time and effort. Typically, a teacher must try more than one intervention before hitting on one that does, in fact, provide a solution.
Second, ideas and advice from others should be sought. Often, another educator (fellow teacher, principal, supervisor, school psychologist, consultant, or student teacher, for example) may offer a workable or adaptable suggestion. Printed materials, including professional books and journals, might be the source of ideas that a teacher may find practical. Although individual teachers often do come up with solutions to their own problems, a fresh perspective on the problem sometimes is needed. Teachers must remember that people-including competent teachers, good parents, and well adjusted children - have occasional difficulty with close interpersonal relationships simply because they cannot step back and view them as an outsider.

Third, teacher-child-peer interrelationships must be considered. Sometimes, focusing intervention on the individual child is sufficient; typically, it is not. Teachers should consider the possibility of employing group contingencies involving two or more children. Many classroom problems involve the entire group's misbehavior. Frequently, an exceptional child in a regular class of low-achieving, disruptive students compounds the management problem, and the regular teacher's skill in handling the situation may be a critical variable in determining the success of a mainstreaming effort for that student.

General strategies for behavior management have been widely published (e.g., Kerr \& Nelson, 1983; Morris, 1985; Smith, 1984; Wallace \& Kauffman, 1986), and behavior management principles now are typically taught in special education teacher training programs. For this reason, we will not outline the most basic management strategies or behavior principles a teacher should know. Rather, we will present some basic considerations required in managing problems involving children and their peers, along with several case reports illustrating successful intervention strategies.

\section{Group Disruption: When to Focus on an Individual}

When one child disrupts the group, the most appropriate intervention is not necessarily a group contingency. The best strategy may be to focus on containing the disruptive student's instigation of misbehavior, perhaps by employing a technique that gets the child actively involved in self-control. In deciding whether to approach the problem with a group-oriented contingency or a plan focused on the individual, the extent to which peers are reinforcing the disruptive child's behavior or launching their own counter-aggression must be assessd.

If disruption almost always begins with the target child 


\section{FIGURE 2 \\ Possible Contributions to Misbehavior: A Checklist of Child Behavior}

Is the child overdependent on you? Children who cannot work independently are a constant source of interruption of the teacher's work and their peers' concentration. Their frequent demands for help, or their refusal to work without the teacher's constant oversight, are wearing on the teacher and may trigger rivalry from peers.

Does the child have difficulty concentrating and paying attention? Learning requires focused attention. A child's lack of attention to task requires additional teacher effort, provides an inappropriate model for peers, raises the probability of disruptive behavior, and lowers the probability of academic success.

Does the child become easily upset under pressure to achieve? The world contains many sources of pressure for productive activity and achievement. Therefore, a classroom without any pressure whatsoever for achievement is an unrealistic and debilitating environment. Children's resistance to expectations for performance is a source of frustration for the teacher and for peers who are striving to achieve.

Is the child's work sloppy? Are responses impulsive? Reflective, careful work is needed in the workplace, and it should be expected in the classroom. Teachers are justified in requiring reasonably neat, thoughtful responses. Teaching is difficult and progress is slow when the child has not learned good work habits and impulse control.

Does the child tease, annoy, or interfere with the work of other students? Annoyance or hassle by neighbors or coworkers is a common and sometimes serious source of stress for adults and children. A child who interferes with the lives of others becomes a source of bad feelings and a sinkhole for the energies of teachers and peers.

Is the child negative toward schoolwork, self, teacher, or peers? Fault-finding, whining, and criticism - whether directed toward others or oneself-induce negative responses in others. These characteristics often are indicative of depression, and they tend to make others feel depressed.

Does the child have poor personal hygiene or habits of self-care? People, young or old, who are dirty or smelly are less likely to be approached socially or to be befriended by others than are those who maintain good hygiene and self-care. Teachers will have difficulty being positive toward children whose odor or appearance is offensive.

Is the child unusually withdrawn or reticent? A withdrawn or reticent child is easily overlooked by teachers and peers. A child with those characteristics is unlikely to be drawn into positive, reciprocal social exchanges without special intervention.

Does the child engage in self-stimulation or self-injury? Excessive or socially inappropriate self-stimulation is incompatible with learning and social acceptance. Self-stimulation and self-injury usually are off-putting to others and inhibit normal psychological and physical development.

Is the child aggressive toward teachers or peers? Aggression in the form of verbal threats, intimidation, extortion, or physical attack heightens anxiety and stress in all parties involved. An aggressive child can be expected to induce hostility and counter-aggression in others. 
and peers offer relatively little reinforcement for the target child's disruptive behavior, the most efficient plan may be to intervene with the target child alone. The following case illustrates a special education teacher's management of an individual child who was disrupting the class. ${ }^{1}$

$* * *$

LaRouche, a 13-year-old from a low-income family, was enrolled in my seventh-grade class for the mildly mentally retarded. A highly distractible child, he often sought attention through inappropriate behavior such as mumbling snide remarks, and he was in continual motion-a real treat to teach! His parents usually cooperated in attending parentteacher conferences. Unfortunately, however, they tended to respond to LaRouche's school problems with physical punishment. Therefore, I have tried to manage his behavior in school without involving the parents.

In my classroom LaRouche was on a behavior contract. One provision of his contract was that he would lose 3 points for any specified infraction of classroom rules of which he was aware. This provision applied not only to my special education class but to his exploratory classes (where he was mainstreamed) as well.

A specific problem with which I had to deal recently was that LaRouche, when seated close to his friends, had a tendency to provoke a particular female student (B. T.) by mumbling verbal abuse regarding her history of head lice. Whenever LaRouche mumbled "tinder bugs," a verbal battle began, the rest of the class "grasped the moment" (to put it mildly), and LaRouche and his friends were off-task for several minutes.

My first move in trying to resolve this problem was to ask B. T. to ignore LaRouche's remarks. I also seated LaRouche in the front of the class near the position I assume most frequently when I am teaching. This seemed the simplest, most obvious tactic. Unfortunately, it was not efective in dealing with the problem. My records showed that LaRouche and company averaged about 12 to 14 "tinder bugs" incidents per day before I changed the seating arrangement; we were still having about 8 to 10 per day.

The second intervention was to continue to encourage B. T. to ignore LaRouche's remarks but to arrange an explicit contingency in his contract, as follows: I tapped him on the shoulder each time he made a remark directed to B. T.- -a

\footnotetext{
${ }^{1}$ This case was described by Gena C. Johnson, a special education teacher in Orange County, Virginia.
}

signal that he had lost 3 points. At first this seemed to be working, but within a week LaRouche was up to his old tricks again, 8 to 10 times per day.

My third try was to seat LaRouche in the back of the room, away from the group, to continue taking points off his daily contract for inappropriate remarks, and to position his seat facing the chalkboard, where I wrote his daily schedule. Every 10 minutes LaRouche was allowed to write his initials on the board if he had remained on-task and not made any inappropriate remarks. His schedule included 8 half-hour periods, meaning that he could write his initials up to 24 times each day. I explained to him that he could exchange the initials for tangible rewards, such as pencils, ink pens, notebook paper, erasers, or other items. The minimum number of initials required for earning a reward on any given day was 21 , allowing for a few slips. With this arrangement, LaRouche's "tinder bugs" incidents dropped to 2 or fewer per day.

LaRouche was thrilled with the tangible rewards he earned. In addition, just getting to write his initials on the board was a reinforcer for him.

The case of LaRouche illustrates the management of disruptive behavior that involved peers by concentrating on the individual child who was the source of disruption. It also illustrates a teacher's discovery that reinforcement of desirable conduct (Deitz \& Repp, 1983) was more effective than response cost punishment (Walker, 1983). Moreover, the case shows that simple, low-cost interventions can be highly effective in resolving seemingly intractible problems.

\section{Group Disruption: The Use of Group-Oriented Contingencies}

When misbehavior is widespread in a group and pinpointing a single instigator of disruption is difficult, a grouporiented contingency may be the intervention of choice. Group-oriented contingencies make use of peer pressure-a phenomenon all teachers recognize but that many do not use to best advantage in the classroom. Ideally, a teacher should strive to prevent negative peer pressure (e.g., students getting peers' attention for clowning) and use positive peer pressure to encourage achievement and appropriate behavior. A variety of group-oriented procedures have been devised, only a few of which will be briefly described here 
(see Greenwood \& Hops, 1981, for further discussion).

\section{Independent or Standardized Group Contingencies}

Standarized contingencies are those that apply to individual students regardless of the performance of the group. A contingency of this type is group-oriented only in that it applies to each member of the group equally. An advantage of an independent contingency is that no child is penalized for the behavior of anyone else; each child receives the reward or punishment he or she alone has earned, and each child has access to rewards or suffers punishment under exactly the same terms. A distinct disadvantage, however, is that peer pressure is unlikely to be harnessed because one child's behavior in no way influences the consequences for another.

\section{Dependent Group Contingencies}

Dependent group contingencies are those under which consequences for a group of students depend on the performance of one member of the group (or, perhaps, a small subgroup). This type of arrangement makes peer pressure much more likely than under an independent contingency. An example of a dependent group contingency is the "hero procedure" used by Patterson (1965). Patterson and his colleagues made "heros" of hyperactive, disruptive students by allowing them to earn rewards for paying attention and behaving appropriately-rewards that were shared with the entire class.

A well executed dependent group contingency can have a distinct advantage: Problem students' peers tend to "root for" them and do what they can to encourage improvement because they have something to gain by doing so. A disadvantage is that it can easily be mismanaged, resulting in possible threats, criticism, or harassment from peers when the target student or subgroup does not perform adequately.

\section{Interdependent Group Contingencies}

Interdependent group contingencies are those in which the same requirements apply to all members of the group but consequences depend on the combined or total performance of the group. Group members must work together to earn a reward in which they all share equally. An example of an interdependent group contingency is the "good behavior game" (Barrish, Saunders, \& Wolf, 1969), which has been used in a variety of forms by several research groups (Greenwood \& Hops, 1981). The essential features of the game are as follows: (1) The teacher states certain rules that apply to all members of the class, (2) all members of the class can earn points for the class (or their "team," a subgroup of the class) by behaving according to the rules, and (3) the class (or team) earns rewards, depending on the number of points earned. In some cases the class or team has earned rewards for accumulating fewer than a certain number of points, which were given for specific misbehaviors; in other cases, the class or team has been rewarded for accumulating greater than a certain number of points for appropriate conduct.

An interdependent contingency, when it is used skillfully, has the advantage of appropriate peer pressure and competition. A possible disadvantage is negative peer reaction when success of the group is spoiled by too high expectations or by persistent misbehavior of a single individual or small group.

Teachers who use group-oriented contingencies can guard against negative peer pressure in several ways: (1) being sure that the performance standard for reward is not too high-beginning with a criterion that can be reached easily and gradually increasing the requirement for reward; (2) emphasizing reward for appropriate behavior rather than punishment for misbehavior; (3) encouraging everyone to participate in the group-oriented contingency but not requiring participation; (4) keeping the competition fair by making certain the teams are about equal in ability to perform; and (5) allowing for students who do not work well in a group competition and eliminating saboteurs from the contingency.

Skillful use of group-oriented contingencies can play a major role in preventing referral of students for special education and in successfully mainstreaming identified exceptional children. If a regular classroom teacher finds more effective means of controlling disruptive behavior, it is less likely that a given student in that class will be referred, and it is more likely that a mainstreamed student will be successful in that class. The following case illustrates a regular classroom teacher's use of an interdependent group-oriented approach. $^{2}$

\section{$* * *$}

As a first-year math teacher instructing seventh and eighth

\footnotetext{
${ }^{2}$ This case was described by John Jeanes, a regular education teacher in Orange County, Virginia.
} 
graders, I soon became aware of the fact that effective behavior management is a key element in successful instruction. For the most part, my classes fairly quickly came under stimulus control. One of my eight classes, however, did not, and I had to take special steps to remedy the situation.

The class consisted of 24 students, one of whom was labeled learning disabled. This was a mixed group in terms of achievement-12 students on grade level and 11 above. The class met during the last period of the school day, when students are often tired and cranky. During the day these students had only one 30-minute break (for lunch) and approximately 25 minutes of physical activity during gym. The classroom was small for the number of students and desks, and temperature control was poor (the room was often unbearably hot and stuffy). In addition, the school was constructed with relatively "open" classrooms, such that passersby were a constant source of disruption.

The less desirable behaviors of these students included physical aggression, out-of-seat, talking out, off-task, and rudeness to each other, as well as to me. Two factors were of primary importance in selecting a behavior management system for this class. First, as a public school teacher, I carried a heavy class load, so it was important to find a system that not only would be effective but also would demand a minimum amount of time for implementation. In this respect a group-oriented contingency was appealing, in that it would require less time and record keeping than a token economy or similar system. Second, taking into account the dynamics, an interdependent contingency was most attractive, since the majority of students in the class supported and encouraged disruptive behavior.

As targets for intervention, I chose two high-incidence behaviors that are incompatible with academic learning: talking out and out-of-seat. I defined talking out as any vocalization, verbal or nonverbal, made without the student having raised his or her hand and receiving my verbal recognition. I defined out-of-seat as a student's buttocks losing contact with the chair or movement of the chair from its position in front of the desk. For purposes of assessment and intervention, however, I considered these behaviors together as disruptions. My aide and I recorded disruptions daily so that we could report the level of the problem to the class and assess any change resulting from our intervention. We kept separate records of disruptions during direct instructional time and seatwork.

Our 5 days of baseline showed that disruptive behavior was occurring about 6.5 times per minute-about 260 incidents per class period! I explained my concern to the students, and during a discussion of the problem we agreed on a plan for trying to get it under control. The immediate criterion we agreed upon was that disruptions should be reduced to no more than 50 per class period. The long-term goal was to reduce disruptions to no more than 7 per period. We agreed that if the class could meet the criterion for a given day, the students would all share a positive reinforcer -5 minutes of free time at the end of the period, during which they could do as they pleased as long as they were orderly and kept their voices down to a reasonable level.

The students immediately showed enthusiasm for the plan, and it was immediately successful. The criteria we set were 50 the first day, 20 the second, then $15,12,10,8$, and 7 . The class occasionally did not meet the criterion. Once the criterion had been exceeded on a given day, the students thought they had nothing to gain by behaving appropriately, and their behavior reverted back to baseline levels. To deal with this difficulty, I incorporated an additional reinforcer: a "free day" with a group-selected video contingent upon the cumulative average target behavior being met within criterion over a specified period of time. This feature kept the group from losing control because students had "blown it" for the day (that is, they still had something to work for).

All in all, I would have to say that the group-oriented contingency I used was an unqualified success. Not only did disruptive behavior decline dramatically, but academic performance improved as well. A few minutes of free time at the end of each class period and an occasional "free day" seems a small price to pay for the instructional time and improved behavior that were gained.

$$
* * *
$$

We now exmine a somewhat more complex case in which teachers, a target child, and the child's regular class peers found it necessary to work out a solution to a problem involving their interrelationships. The following case illustrates use of an interdependent group contingency and a self-control strategy. ${ }^{3}$

$$
* * *
$$

James, a 9-year-old, came to my first-grade class in November. He previously had been enrolled in two other schools in the area and had been retained in first grade. He was visually impaired and wore very thick glasses. His glasses corrected his vision adequately for mobility, but he

\footnotetext{
${ }^{3}$ This case was managed by author Akers with the assistance of author Pullen.
} 
held his face very close to his reading material and had acquired the habit of reading over his glasses. He felt more secure being placed close to the board or at the front of the group in any presentation in the auditorium.

In addition to his visual impairment, James suffered from an asthmatic condition that was aggravated by some weather conditions. His mother reported that he could not attend school in Wisconsin, where they had lived previously, because of the severe winter cold. Consequently, he had received homebound instruction there.

James was smaller than most of the other children, and his physical unattractiveness was a problem. His long, dirty hair, thick smudged glasses, dirty clothing, and unpleasant odor made him the target of other children's teasing. Even though they teased him, James truly seemed to want to be friends with other children. He discovered that he could attract his peers' attention not only by his appearance but by his silly and gross antics, such as falling out of his chair, crawling on the floor, making loud animal-like noises, eating like a dog, and picking his nose. Other children responded to his behavor by laughing or by commenting on how disgusting he was, or both. He loved other children's attention, positive or negative.

Part of the problem in managing James's behavior was created by the composition of the class: 16 boys and 7 girls. Six of the boys had been retained, were physically larger than James, had been together in the same class for 2 years, and enjoyed having a victim or scapegoat.

Academically, James was more advanced than the reading group in which he was placed initially. He therefore went to another teacher for reading and stayed with me for math, spelling, language, health, and home room. He went to other teachers for science, social studies, art, music, and physical education. James could make exceptional contributions to class discussions, but he disliked the routine type of work required in handwriting and math.

James had a short attention span and was easily distracted. When he tired of doing his assignments, he drew pictures, distracted others, or engaged in other forms of inappropriate behavior, as described previously. He was unable to function in any large-group setting, and he had difficulty adjusting to special teachers (e.g., music, art, physical education), from whom I received many complaints about his misbehavior.

I tried several positive behavior modification techniques with James-all with limited success. For example, I used "Happy Grams" (positive smiling-face notes home) daily (something I use in an ongoing system with the entire group). I also tried class meetings in which we discussed James's behavior, parent conferences, daily notes home, and frequent compliments for appropriate behavior. A long conference with his mother-who was not fastidious herself and who did not see James's cleanliness and appearance as her responsibility - finally did result in some improvement in his appearance and hygiene. This resulted in somewhat better treatment from his peers. Significant behavior problems persisted, however, and I was ready to try anything new.

Pat and I discussed a combination of self-monitoring and an interdependent group contingency. We devised a means of monitoring the behavior of the entire class and a selfmonitoring procedure for James. I made a large chart on the chalkboard, divided into two sections. I put a smiling face on one side of the chart whenever everyone ignored one of James's inappropriate behaviors. If a classmate responded in any way to the behavior, I put an X on the other side of the chart. Initially, I also praised the individual or the entire group when making the smiling face, commenting on the specific desirable peer behavior (e.g., "I'm proud of Chris because he kept right on working on his math sheet" when James tried to distract him). When I made an X on the chart, I almost never called attention to the guilty party. The class knew who was responsible.

Quite soon I saw peer pressure operating to get smiling faces and to keep the class from getting Xs. Clearly, James was getting less reinforcement from his peers, and the class was looking forward to receiving a reward. I had promised the class that if, at the end of the week, the smiling faces outnumbered the Xs, everyone would be able to participate in a special treat-a sing-along with Ms. Pullen, who would bring her guitar and teach them new songs.

James's self-monitoring involved his keeping smiling faces and Xs in a folder. He made his own smiling faces for behaving appropriately, and his own Xs for misbehavior. $\mathrm{He}$ took pride in maintaining his folder and was extremely trustworth in recording. In the beginning, I gave him a nod for inappropriate behavior and praised him for desirable behavior, signaling him what to record.

Eventually James began to make his own judgments about the acceptability of his behavior, and his smiling faces increased while his Xs decreased. In addition, his attention span increased and the quality of his academic work improved. I also received more good reports from his special teachers, who were quite receptive to the idea of selfmonitoring. Through it all, James seemed to acquire a much improved self-image and to obtain a sense of accomplishment. 


\section{SUMMARY}

Both teachers and pupils can contribute to problems of behavior management. Teachers' and children exert reciprocal influence. Management is not simply a matter of teachers managing children. Teachers' introspection may indicate ways in which their own behavior might foster the misbehavior of their students. Although certain pupil characteristics may produce stress for the teacher and classroom peers and contribute to undesirable teacher and peer conduct, the teacher generally is responsible for initiating intervention to improve children's behavior.

Intervention should be as simple and direct as possible. Ideas and suggestions of other professionals should be sought when difficulties are encountered, and teacher-child-peer relationships should be carefully considered in selecting interventions. When a group disruption is primarily the result of one child's misconduct, the most appropriate intervention may focus on that individual. When all or many members of the group are disruptive, group-oriented contingencies are typically the intervention of choice. A target child whose misbehavior involves many members of the class often may be managed by a combination of self-control and interdependent group contingency strategies. Group management skills are particularly important in maintaining exceptional children in regular classes, where teacher-child-peer relationships are critical to successful mainstreaming.

\section{REFERENCES}

Barrish, H. H., Saunders, M., \& Wolf, M. M. (1969). Good behavior game: Effects of individual contingencies for group consequences on disruptive behavior in a classroom. Journal of Applied Behavior Analysis, 2, 119-124.

Deitz, D. E. D., \& Repp, A. C. (1983). Reducing behavior through reinforcement. Exceptional Education Quarterly, 3(4), 34-46.

Graubard, P. S., Rosenberg, H., \& Miller, M. (1971). Ecological approaches to social deviancy. In B. L. Hopkins \& E. Ramp (Eds.), A new direction for education: Behavior analysis 1971. Lawrence: Kansas University Department of Human Development.

Greenwood, C. R., \& Hops, H. (1981). Group-oriented contingencies and peer behavior change. In P. S. Strain (Ed.), The utilization of classroom peers as behavior change agents. New York: Plenum.

Hobbs, N. (1966). Helping the disturbed child: Psychological and ecological strategies. American Psychologist, 21, 1105-1115.

Kauffman, J. M. (1985). Characteristics of children's behavior disorders (3rd ed.). Columbus, $\mathrm{OH}$ : Charles E. Merrill.

Kerr, M. M., \& Nelson, C. M. (1983). Strategies for managing behavior problems in the classroom. Columbus, $\mathrm{OH}$ : Charles E. Merrill.

Lloyd, J. W. (1984). How shall we individualize instruction-or should we? Remedial \& Special Education, 5(1), 7-15.

Morris, R. J. (1985). Behavior modification with exceptional children. Glenview, IL: Scott, Foresman.

Patterson, G. R. (1965). An application of conditioning techniques to the control of a hyperactive child. In L. P. Ullmann \& L. Krasner (Eds.), Case studies in behavior modification. New York: Holt, Rinehart, \& Winston.

Rhodes, W. C. (1967). The disturbing child: A problem of ecological management. Exceptional Children, 33, 449-455.

Rhodes, W. C. (1970). A community participation analysis of emotional disturbance. Exceptional Children, 37, 309-314.

Smith, D. D. (1984). Effective discipline. Austin, TX: Pro-Ed.

Stevens, R., \& Rosenshine, B. (1981). Advances in research on teaching. Execeptional Education Quarterly, 2(1), 1-9.

Strain, P. S., Odom, S. L., \& McConnell, S. (1984). Promoting social reciprocity of exceptional children: Identification, target behavior selection, and intervention. Remedial \& Special Education, 5(1), 21-28.

Swift, M. S., \& Spivack, G. (1969). Clarifying the relationship between academic success and overt classroom behavior. Exceptional Children, $36,99-104$.

Swift, M. S., \& Spivack, G. (1973). Academic success and classroom behavior in secondary schools. Exceptional Children, 39, 392-399.

Walker, H. M. (1983). Applications of response cost in school settings: Outcomes, issues and recommendations. Exceptional Education Quarterly, 3(4), 47-55.

Wallace, G., \& Kauffman, J. M. (1986). Teaching students with learning and behavior problems (3rd ed.). Columbus, $\mathrm{OH}$ : Charles E. Merrill.

\section{Professional update}

\section{SOFTWARE CATALOG FOR LD STUDENTS' NEEDS}

Special Times is a free catalog of software selected specifically for K-8 students with learning problems. It includes over 100 software programs produced by more than 30 pub- lishers. The content covers math, language arts, social studies, science, problem solving and critical thinking skills. The software is suggested for mainstreamed classes, resource rooms, or self-contained settings.

This catalog is available from CDL, Dept. S. 1696 Massachusetts Ave., Cambridge, MA 02138. 

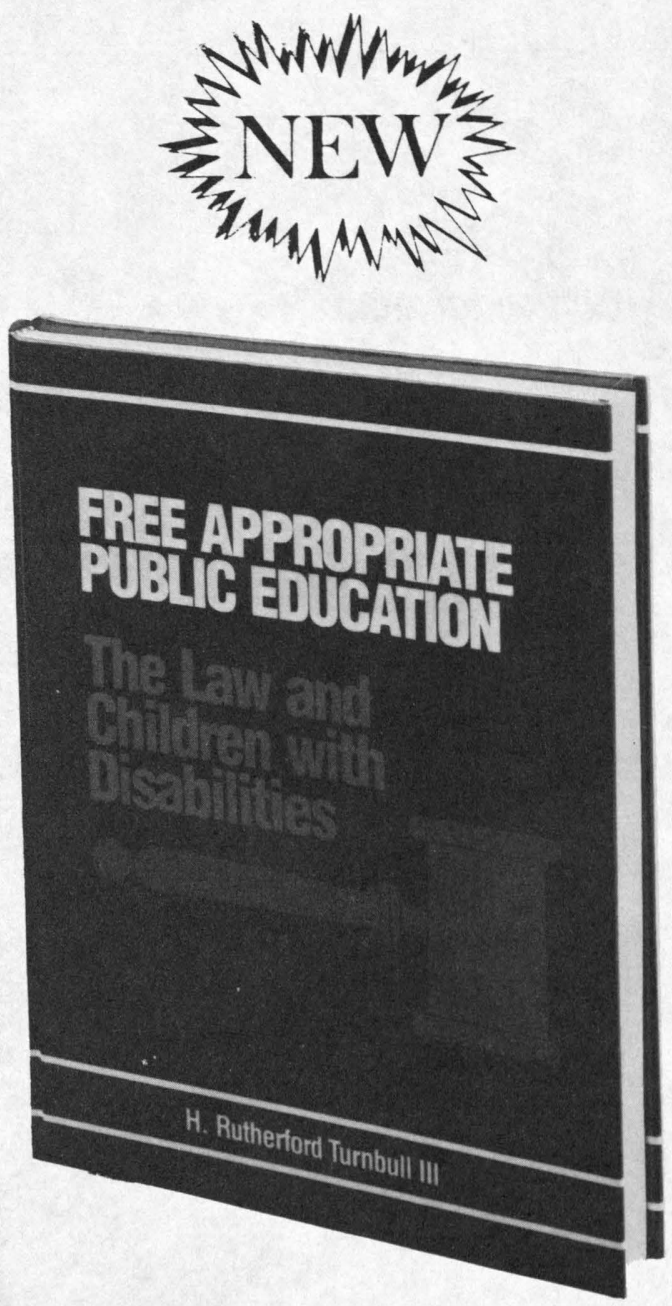

\title{
FREE APPROPRIATE PUBLIC EDUCATION
}

\section{The Law and Children With Disabilities}

\author{
by $\mathrm{H}$. Rutherford Turnbull III
}

University of Kansas

Here is a complete, definitive resource for those concerned with the law and education of children with disabilities. The book covers the six major principles of the law pertaining to education of children with disabilities: zero reject; testing, classification, and placement; individualized and appropriate education; the least restrictive alternative; procedural due process; and parent participation. Each of these principles is addressed according to:

- the constitutional foundations

- legislation

- applicable case laws and precedents

This is a much-needed reference for busy special educators and professionals who do not have time to consult and locate various documents and sources. It is extremely useful and valuable to special education directors, school administrators, school principals, graduate students, attorneys, school board personnel, parents, and, above all, every hearing officer in the nation.

Introductory information includes an overview of the American legal system, historical events leading to this landmark legislation; implications for the public school system; and definitions of disabilities and handicaps. The book concludes with case law techniques, statutory techniques, and a discussion of the American value system. Appendices include transcripts of three significant Supreme Court judgments, glossary, case index and subject index, and a table of the approximately 500 court cases cited.

The book is well organized so you can readily find the information you need. It is without peer. Order your copy today!

No. $8602 / \$ 29.95$ ISBN 0-89108-125-9

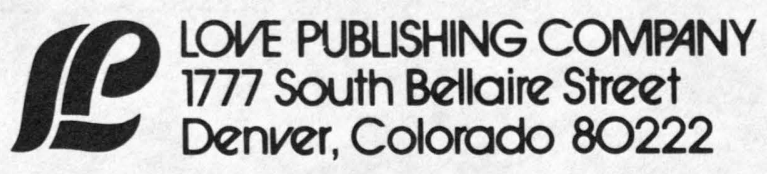




\section{ALERT}

\section{MEETINGS}

- Canadian National Congress

Council for Exceptional Children

October 8-11, 1986

Convention Centre

Hotel Saskatchewan

Regina, Saskatchewan

Canada

(Contact: Larry Carlson 306/787-6052)

- Council for Learning Disabilities

October 9-11, 1986

Kansas City, Missouri

(Contact: Judy Wilson 913/588-5985)

- National Early Childhood Conference

On Children with Special Needs

October 19-21, 1986

Galt House East Hotel

Louisville, Kentucky

(Contact: CEC 703/620-3660)

- National Association for Gifted Children

November 2-7, 1986

Riviera Hotel

Las Vegas, Nevada

(Contact: 612/784-3475)

- American Speech and Hearing Association

November 21-24, 1986

Detroit, Michigan

- Association for Children and Adults

With Learning Disabilities

February 25-28, 1987

San Antonio, Texas

- Pan American Conference on Rehabilitation and Special Education

March 15-18, 1987

Acapulco, Mexico

(Contact: Richard Beck 512/381-2287)

- Council for Exceptional Children

April 20-24, 1987

Chicago, Illinois

\section{AWARD-WINNING RESOURCE}

Childhood Information Resources, compiled by Marda Woodbury, has been selected as one of the "Outstanding Reference Sources of 1985" by the Reference Sources Committee of the Reference and Adult Services Division of the American Library Association. This volume describes and evaluates over 1,100 contemporary sources of information on children from conception through age 12. Among the areas covered are drug abuse, missing children, effects of divorce, poverty, and sexual abuse, handicapped and gifted children, single adoptive parents, and many more child-related topics. The information sources include monographs, data bases, audiovisual catalog media, abstracting and indexing services, and others.

Dr. Benjamin Spock has endorsed the book as "a godsend for ... psychologists, sociologists, lawyers, educators, pediatricians, nurses . . . even inquisitive parents." This resource is available from Information Resources Press, 1700 North Moore St., Suite 700, Arlington, VA 22209.

$$
* * *
$$

\section{NEW BOOK}

\section{Handicapping the Handicapped: \\ Decision Making in Students' Educational Careers}

\section{by Hugh Mehan, Alma Hertweck, and J. Lee Meihls}

This new book, based on field research in a West Coast school district, attempts to explain and understand the process by which elementary school students are categorized and placed. The analysis focuses on three decision-making events - classroom behavior, educational testing situations, and placement committee hearings.

The authors argue that so-called handicaps seem to be generated by society and the educational system itself. Students' school life is demonstrated to be shaped by institutional practices and organizational routines operating in the face of legal, fiscal, and practical constraints. Attention is given to the inconsistency between documented and actual reasons for special education referral.

This hardbound book is published by the Stanford University Press, Stanford, CA 94305. 